\title{
A “NEW ERA" IN RHEUMATISM TREATMENT
}

\section{FOREWORD BY LORD HORDER}

Publication of the Annals of the Rheumatic Diseases as a quarterly journal by the British Medical Association marks a new stage in the British effort, dating back several years, to make a worthy contribution to scientific literature dealing with the problems of rheumatic disease. This new stage is welcomed by the Empire Rheumatism Council as assisting its own aim to promote, among the general body of medical practitioners, the degree of interest which the importance of these problems demands. Rheumatism, because of its wide prevalence and its resulting pain and disablement, is perhaps the most serious enemy of social well-being. To check, and ultimately to end, its ravages is a challenge to all branches of our profession-the family doctor, the specialist, and the research worker.

The Annals have had a decade of not undistinguished history. In the first place they took the form of an annual published by the British Committee on Chronic Rheumatic Disease appointed by the Royal College of Physicians, and edited by C. W. Buckley, M.D., F.R.C.P. Of this annual four numbers were issued, embodying a considerable number of authoritative articles by distinguished contributors. In 1938 that committee passed on its work, including the publication of the Reports, to the Scientific Advisory Committee of the newlyformed Empire Rheumatism Council. An Editorial Committee was constituted of C. W. Buckley, M.D., F.R.C.P., W. S. C. Copeman, M.D., F.R.C.P., A. G. Timbrell Fisher, M.C., F.R.C.S., and Mervyn Gordon, C.M.G., F.R.S., D.M., and the first number of the new series was published in January, 1939.

First as a quarterly and then, when war conditions enforced paper economy, as a half-yearly, the review maintained a high scientific standard. What was among the last important papers from the pen of Ludwig Aschoff appeared in its issue of July, 1939. In 1942 Dr. Philip S. Hench and Dr. Loring T. Swaim of the United States became Associate Editors, and the Annals thus became an AngloAmerican organ of medical research in rheumatism. This year the new series opens and I have confidence that it will carry on the good record of the past with an increasing scope for its educational work.

It is the opportunity for that increasing scope which I want to impress. A new era is opening in the public attitude to the rheumatic diseases. At last there is acknowledged the seriousness of the attack which they make on home happiness and industrial efficiency. The old attitude was a very strange phenomenon. The National Health Insurance Act-purporting to provide for the medical needs of the under-privileged sections of the community-implicitly, if not explicitly, recognized that the efficient treatment of rheumatism called for some special measures other than those available to the general practitioner or the general hospital. Provision was made for the approval by the Ministry of Health of clinics equipped to provide special treatment for rheumatic sufferers; but the number of such approved clinics has up to the present date represented only a " token payment " if we take into consideration the number of sufferers. An Approved Society under the Act could pay for rheumatism treatment if, and only if, its finances were so prosperous that it had a surplus after meeting its other expenses; then rheumatism treatment could be provided as an "Additional Benefit." The effect of these two obstacles was nugatory so far as the great majority of sufferers were concerned. Only those who were insured with a prosperous Society, and were within reach of an approved clinic, could benefit.

Now, the Ministry of Health is pledged to provide for all " treatment appropriate to their needs." We have definite assurances (in Parliament and out of it) that this includes rheumatic sufferers. The White Paper on 'A National Health Service,' neglecting to make specific mention of rheumatism in its short catalogue of diseases, raised doubt in some minds. Was it intended that the word " all " should be construed by the political mind to mean " all, except that very large section of the community which has the misfortune to suffer from rheumatism?" These doubts were subsequently removed by definite assurances. It may be perhaps surmised that the omission of any reference to rheumatism in the White Paper is to be explained by a reluctance to call attention to that very strange phenomenon to which I have just referred, and the consequent necessity to put on the garb of the penitent in confessing to the absurdity of the "Additional Benefit" system. What is very reassuring is the fact that the Minister has quite recently set up a subcommittee of his Medical Advisory Committee to consider the whole position relative to the rheumatism problem and to report to him for his guidance.

But the past may be left as the past and the new era gratefully welcomed, with note of two developments which will be consequential on the decision to provide " treatment appropriate to their needs" to all rheumatic sufferers, instead of, as at present, to only about 10 per cent. of their number. 
The first development will obviously be to make a great additional demand on the medical profession and its auxiliaries. This fact, with its implications, must be squarely faced; otherwise the hope held out to neglected sufferers may prove illusory.

One of those implications the Empire Rheumatism Council recognizes in the plans it is preparing-to promote as soon as practicable a series of postgraduate courses in rheumatism treatment for medical practitioners. The aim of these will be to provide sufficient special knowledge, especially as to the resources of physical medicine, to fit doctors to take charge of local treatment centres with a "reserve" of a few specialized centres to which particularly difficult cases could be referred. These specialized centres would also have the duty of research into the causative factors of the various morbid conditions now classified as rheumatic as well as clinical research into proposed new methods of treatment.

It is my conviction (and that of my colleagues of the Empire Rheumatism Council) that it would be a serious mistake to attempt to divorce rheumatism treatment from the general body of medical practice. I may be permitted on this point to quote the argument supporting it from "Rheumatism-A Plan for National Action," in which it is stressed that the method to be adopted should be consistent with our existing medical system.

"That system assumes that the general practitioner has a sound knowledge of medicine and surgery because, before he can become a qualified doctor, he must submit to a lengthy course of training and prove by examination that he has gained the knowledge which is the fruit of that training. This assumption is justified, with few exceptions; probably there is a lower average of incompetents in the medical than in other professions. In any case we should come to an impasse if we have not faith in the general practitioner as normally skilful in the diagnosis and treatment of human illness. The best resource, indeed, of any sufferer, in the first instance, is the 'family doctor'; he (or she) can deal with the average case and can decide when specialist or institu-

\section{EDITORIAL FOOTNOTE}

The decision of the Empire Rheumatism Council to seek publication of the Annals by the British Medical Association has been responsible for some delay in the issue of the first number of volume iv, and for the new format. It is hoped that this development will increase the circulation of the Annals as the leading publication on rheumatic diseases in the English-speaking countries.

The exigencies of the paper supply will influence the regularity of publication, but it is hoped to maintain quarterly issues. The next number will include a continuation of Lieut.-Colonel W. S. C. Copeman's observations on the experimental transmission of rheumatism, an important paper by Mr. Norman Capener, and a paper from Australia on fibrositis.

In the U.S.A. the establishment of a rheumatism or laboratory. tional advice is necessary. We must accept this or deny the efficacy of our whole medical system.

"Let us decide then, that in the treatment of rheumatic disease it is sound to follow the method of relying on the main body of the medical profession, with reserve forces of rheumatological specialists and institutions at hand to reinforce them as necessary.

"But obviously there is need, and a need which will increase as we get to closer grips with the rheumatic problem, for increase in the number of those specialists ; and an equally urgent need that the general body of practitioners should be encouraged to devote some particular attention to the problems of rheumatic disease. In its treatment the best hope of success rests in the capacity to detect, or at least to suspect (and, following the suspicion, to seek further advice) the first symptoms of rheumatic disease. Like all other ideals, it is, humanly speaking, impossible of complete attainment ; but it must be pursued steadily."

To that argument there might be added, with reference to the past rather than the future, that it has not been the fact that the "family doctor," in general, was ignorant of the particular means needed for the treatment of some forms of rheumatic disease. It was, rather, the fact that it was futile to prescribe treatment which it was impossible for the patient, in the majority of cases, to obtain. The provision of treatment Centres was thus a first necessity.

The second development is full of hope for the future. With the provision of treatment "appropriate to their needs" for rheumatic sufferers there will become possible that early attention to a condition causing or threatening the development of rheumatism, which is the primary need. There will also be provided the facilities (not at present existing to anything like the necessary extent) for intensive and effectively controlled clinical research to evaluate accurately the efficiency of present methods and proposed new methods of treatment.

In this new era of promise it may well be that the Annals, in some near future number, can chronicle a steady diminution of the ravages of rheumatic disease.

HORDER.

centre at the Army and Navy General Hospital, Hot Springs, Arkansas, is an important step. It is hoped to publish a full account of this. In a letter to the Chairman of the Empire Rheumatism Council, Lord Horder, Lieut.-Colonel Hench mentions that a small-scale research has just been completed on the effect of penicillin on rheumatoid arthritis. High doses were given for fairly long periods of time without result. Several groups of doctors have used penicillin for rheumatic fever, but again without result; one physician made the pungent remark: "The use of penicillin allows one to study the natural course of events in rheumatic fever."

The Editors will be glad to consider for publication in the Annals papers on the rheumatic diseases, and especially reports on research work, either clinical 